УДК 621.3.036.27-0,32.2

\title{
THERMAL DISTRIBUTION IN FORCED MOVEMENT OF WATER IN PIPES, CHANNELS AND ALONG THE FLAT WALL
}

\author{
D. Sinat-Radchenko, N. Ivashchenko, S. Vasilenko \\ National University of Food Technologies
}

\begin{tabular}{|c|c|}
\hline Key words: & ABSTRACT \\
\hline $\begin{array}{l}\text { water, } \\
\text { forced movement, } \\
\text { pipes and channels, } \\
\text { flat walls, } \\
\text { flow modes, } \\
\text { heat transfer coefficients }\end{array}$ & $\begin{array}{l}\text { The movement of water in pipes and canal can be laminar, } \\
\text { turbulent and transient condition. The nature of the flow is } \\
\text { determined by the Reynolds number. Different criteria equa- } \\
\text { tions are used in each of these modes to calculate the heat } \\
\text { transfer coefficient } \alpha\left(\mathrm{W} /\left(\mathrm{m}^{2} \cdot \mathrm{K}\right)\right) \text {. } \\
\text { Heat transfer criteria equation have the form } \mathrm{Nu}=\end{array}$ \\
\hline $\begin{array}{l}\quad \text { Article history: } \\
\text { Received 09.10.2019 } \\
\text { Received in revised form } \\
05.11 .2019 \\
\text { Accepted } 21.11 .2019\end{array}$ & $\begin{array}{l}\mathrm{CRe}^{\mathrm{n}} \operatorname{Pr}^{\mathrm{m}} \varepsilon_{\mathrm{q}} \\
\text { The Nusselt criterion required (it includes } \alpha) \text { is } \mathrm{Nu}=\alpha \mathrm{d} / \lambda \text {, } \\
\text { where } \lambda \text { is the thermal conductivity of the liquid, }(\mathrm{W} /(\mathrm{m} \cdot \mathrm{K})) \text {. } \\
\text { The Prandtl number } \operatorname{Pr}=v / \text { a characterizes the thermo-physical } \\
\text { properties of the liquid, and a is the thermal diffusivity of the }\end{array}$ \\
\hline $\begin{array}{l}\text { Corresponding author: } \\
\text { vinci@ukr.net }\end{array}$ & $\begin{array}{l}\text { liquid, } \mathrm{m}^{2} / \mathrm{s} \text {; the correction } \varepsilon_{\mathrm{q}} \text { takes into account the heat flux } \\
\text { and the temperature head value. } \\
\text { For the viscous-gravitational regime the Grashof number } \\
\mathrm{Gr}=\mathrm{gd}^{3} \beta\left(\mathrm{t}_{\mathrm{c}}-\mathrm{t}\right) / \mathrm{v}^{2} \text { is added. } \\
\text { The equations for calculating the heat transfer coefficients } \\
\text { include the thermo-physical properties of water. For the tempe- } \\
\text { rature range } 0 \ldots 130^{\circ} \mathrm{C} \text {, which is most used in the food indus- } \\
\text { try, we obtained simple, accurate calculation formulas (the limit } \\
\text { relative error within one percent) for } \lambda \text {, } v \text {, Pr, etc.; correction } \\
\text { formula for the length of short pipes; intermittency coefficient } \\
\text { of transient condition. } \\
\text { We have proposed ready-made formulas for calculating heat } \\
\text { transfer coefficients during forced water movement in pipes, } \\
\text { channels and along a flat wall. Numerical examples of calcu- } \\
\text { lating heat transfer coefficients for various modes of water } \\
\text { movement in a pipe and water movement along a flat wall are } \\
\text { given. } \\
\text { The calculation results } \alpha \text { according to the formulas we have } \\
\text { proposed and based on the criteria equations practically coin- } \\
\text { cide. Our method does not require the use of any tables and in- } \\
\text { terpolations. This facilitates and accelerates the determination } \\
\text { of the heat transfer coefficient. This makes the determination of } \\
\text { the heat transfer coefficient simpler and faster. }\end{array}$ \\
\hline
\end{tabular}

DOI: $10.24263 / 2225-2916-2019-26-19$

() Д. Є. Сінат-Радченко, Н. В. Іващенко, С. М. Василенко, 2019 


\title{
ТЕПЛОВІДДАЧА ЗА ВИМУШЕНОГО РУХУ ВОДИ В ТРУБАХ, КАНАЛАХ І ВЗДОВЖ ПЛОСКОЇ СТІНКИ
}

\author{
Д. Є. Сінат-Радченко, канд. техн. наук \\ Н. В. Іващенко, канд. техн. наук \\ С. М. Василенко, д-р. техн. наук \\ Національний університет харчових технологій
}

На основі узагальнення даних з теплофрізичних властивостей води та аналізу ії тепловіддачі за вимушеного руху в трубах, каналах і вздовж плоскої стінки для інтервалу температур $0 \ldots 130^{\circ} \mathrm{C}$ та різних умов і режимів руху води запропоновано ряд простих, але досить точних фрормул (i числових прикладів їх використання) для розрахунку коефіцієнтів тепловіддачі без використання будь-яких таблиць та інтерполяції. Це полегшує та прискорює інженерні розрахунки і дає змогу використовувати фрормули у різноманітних комп'ютерних програмах.

Ключові слова: вода, вимушений рух, труби і канали, плоскі стінки, режими течії, коефріцієнти тепловіддачі.

Постановка проблеми. Тепловіддача за вимушеного руху води в трубах, каналах і вздовж плоскої стінки залежить від геометрії поверхні теплообміну, режиму течії води, температур води і стінки, теплофізичних властивостей води, напряму теплового потоку тощо. Врахувати вплив усіх факторів - складна завдання. Водночас бажано спростити розрахунки процесів теплообміну.

Метою досліджень $\epsilon$ аналіз сучасного стану розрахунків тепловіддачі за вимушеного руху води в трубах, каналах і вздовж плоскої стінки та пошук можливостей спрощення цих розрахунків.

Методи дослідження грунтуються на основі узагальнення теплофізичних властивостей води простими, але достатньо точними розрахунковими формулами, одержанні розрахункових формул для поправкових коефіцієнтів, виключенні потреби в користуванні будь-якими таблицями, можливості використання простих комп'ютерних програм для варіантних розрахунків.

Результати досліджень. Рух води в трубах і каналах може бути ламінарним i турбулентним (вихровим). Характер течії визначається числом Рейнольдса $R e=$ $\omega \mathrm{d} / \mathrm{v}$, де $\omega$ - середня по перерізу труби швидкість води, м/c; d - внутрішній (еквівалентний) діаметр (визначальний лінійний розмір), м; v - кінематична в'язкість води, $\mathrm{M}^{2} / \mathrm{c}$.

За $\operatorname{Re} \leq 2300$ режим течії ламінарний, за $\operatorname{Re} \geq 10^{4}$ - турбулентний, а при $2300<\operatorname{Re}<10^{4}$ — перехідний. У кожному 3 цих режимів для розрахунку коефіцієнта тепловіддачі $\alpha\left(\mathrm{BT} /\left(\mathrm{M}^{2} \cdot \mathrm{K}\right)\right)$ використовують свої критеріальні рівняння та добуток поправок на конкретні умови теплообміну. Обов'язково вказується визначальна температура, за якої враховуються теплофізичні параметри води. Ми розглянемо розрахунок $\alpha$ для найчастіше використовуваного у харчовій і мікробіологічній промисловості інтервалу температур води від 0 до $130^{\circ} \mathrm{C}$.

Ламінарна течія може відбуватися за відсутності природної конвекції (тепло передається лише теплопровідністю). Такий режим течії називають в'язкісним. Він імовірний за малих $d$, великої $v$ і малої різниці між температурами стінки $і$ рідини $\Delta \mathrm{t}=\mathrm{t}_{\mathrm{c}}-\mathrm{t}=\mathrm{T}_{\mathrm{c}}-\mathrm{T}(\mathrm{T}, \mathrm{K}-$ абсолютна температура). 
У цьому випадку для визначення середнього коефіцієнта тепловіддачі в прямих гладких трубах використовують критеріальне рівняння:

$$
\mathrm{Nu}=\mathrm{CRe}^{\mathrm{n}} \operatorname{Pr}^{\mathrm{m}} \varepsilon_{\mathrm{q}}=0,15 \operatorname{Re}^{0,33} \operatorname{Pr}^{0,43} \varepsilon_{\mathrm{q}} \text {. }
$$

$\mathrm{У}$ шуканий критерій подібності Нуссельта $\mathrm{Nu}=\alpha \mathrm{d} / \lambda$ входять $\alpha$, d та теплопровідність води $\lambda$, Вт/(м·К). Число Прандтля $\mathrm{Pr}=\mathrm{v} / \mathrm{a}$ характеризує теплофізичні властивості води (а - коефіцієнт температуропровідності, м²/c). Поправка $\varepsilon_{\mathrm{q}}=\left(\operatorname{Pr} / \operatorname{Pr}_{\mathrm{c}}\right)^{0,25}$ враховує напрям теплового потоку (нагрівання, охолодження) та величину температурного напору $\left(\mathrm{t}_{\mathrm{c}}-\mathrm{t}\right)$.

Залежно від умов руху води у рівнянні (1) коефіцієнт С і показник степеня при $\mathrm{Re}$ «n» змінюються, а показник степеня при $\mathrm{Pr}$ «m» для розглядуваних процесів дорівнює 0,43 і $\operatorname{Pr}^{0,43}\left(\operatorname{Pr}_{2} / \operatorname{Pr}_{\mathrm{c}}\right)^{0,25}=\operatorname{Pr}^{0,68} \cdot \operatorname{Pr}_{\mathrm{c}}{ }^{-0,25}[1,2]$.

Коефіцієнт тепловіддачі у в'язкісному режимі:

$$
\alpha_{\mathrm{B}}=0,15 \lambda \omega^{0,33} \mathrm{~d}^{-0,67} v^{-0,33} \operatorname{Pr}^{0,68} \operatorname{Pr}_{\mathrm{C}}^{-0,25} \text {. }
$$

3 появою природної конвекції в'язкісний режим течії переходить у в'язкісногравітаційний, а критеріальне рівняння доповнюється числом Грасгофа $\mathrm{Gr}=\mathrm{gd}^{3} \beta\left(\mathrm{t}_{\mathrm{c}}-\mathrm{t}\right) / v^{2}$, яке характеризує інтенсивність вільної конвекції:

$$
\mathrm{Nu}=0,15 \mathrm{Re}^{0,33} \mathrm{Gr}^{0,1} \operatorname{Pr}^{0,68} \cdot \operatorname{Pr}_{\mathrm{c}}^{-0,25} \text {. }
$$

У критерії Грасгофа g=9,807 м²/c - прискорення вільного падіння; $\beta=\left(\rho / \rho_{\mathrm{c}}-1\right) /\left(\mathrm{t}_{\mathrm{c}}-\mathrm{t}\right)$ - температурний коефіцієнт об' ємного розширення води, $\mathrm{K}^{-1}$; $\rho$ та $\rho_{c}$ - густина води за середніх температур води і стінки, кг $/ \mathrm{M}^{3}$.

В інтервалі температур $-15 . . .130^{\circ} \mathrm{C} 3$ граничною відносною похибкою $\delta \rho=0,05 \%$ :

$$
\rho=\left(0,001+1,3 \cdot 10^{-8}|\mathrm{t}-4|^{1,778}\right)^{-1} \text {. }
$$

Перехід від в'язкісного до в’язкісно-гравітаційного режиму відбувається за умови, коли Gr·Pr $>8 \cdot 10^{5}$. Завдяки природній конвекції $\alpha$ може збільшуватися у декілька разів.

Урівняння розрахунку коефіцієнтів тепловіддачі входять теплофізичні параметри води [3-5]. Для розглядуваного інтервалу температур пропонуються прості, але досить точні розрахункові формули (граничні відносні похибки в межах одного відсотка)

Теплопровідність води, Вт/(м·К):

Кінематична в'язкість , $\mathrm{m}^{2} / \mathrm{c}$ :

$$
\lambda=(0,603-28,73 /(t+100))^{0,5} \text {. }
$$

Число Прандтля:

$$
v \cdot 10^{9}=\exp (0,2905-42,47 / \mathrm{T})^{-1} \text {. }
$$

Число Рейнольдса:

$$
\operatorname{Pr}=10^{-2} \exp (0,3434-55,92 / \mathrm{T})^{-1} \text {. }
$$

Число Грансгофа:

$$
\operatorname{Re}=10^{9} \omega \mathrm{d} / \exp (0,2905-42,47 / \mathrm{T})^{-1}
$$

$$
\mathrm{Gr}=\mathrm{gd}^{3} \beta\left(\mathrm{t}_{\mathrm{c}}-\mathrm{t}\right) \mathrm{Fu},
$$

при цьому $\mathrm{Fu}=\beta / \mathrm{v}^{2}=\exp \left(27,2-549 / \mathrm{t}_{\mathrm{p}}-87476 / \mathrm{t}_{\mathrm{p}}{ }^{2}+5,16 \cdot 10^{6} / \mathrm{t}_{\mathrm{p}}{ }^{3}\right)-1 \cdot 10^{8}$, де $\mathrm{t}_{\mathrm{p}}=(\mathrm{t}+100)$ - розрахункова температура.

Наприклад, якщо $\mathrm{t}=60^{\circ} \mathrm{C}$, то $\mathrm{t}_{\mathrm{p}}=160^{\circ} \mathrm{C}, \mathrm{Fu}=2,33 \cdot 10^{9} \mathrm{c}^{2} /\left(\mathrm{M}^{4} \cdot \mathrm{K}\right), \mathrm{a} \mathrm{Fu}^{0,1}=8,644$. При $4^{\circ} \mathrm{C} F u=0$ (бо $\beta=0$, а при $\mathrm{t}<4^{\circ} \mathrm{C} \beta$ від'ємний). За $\mathrm{t}=60^{\circ} \mathrm{C} \rho=983,6 \kappa \Gamma / \mathrm{m}^{3}$; $\lambda=0,650 \mathrm{BT} /(\mathrm{M} \cdot \mathrm{K}) ; \mathrm{v}=477 \cdot 10^{-9} \mathrm{M}^{2} / \mathrm{c} ; \operatorname{Pr}=2,98$. При $110^{\circ} \mathrm{C} \operatorname{Pr}=1,583$. 
Коефіцієнт тепловіддачі у в'язкісно-гравітаційному режимі на основі формули (3):

$$
\alpha_{\mathrm{Br}}=0,188 \lambda \omega^{0,33} \mathrm{~d}^{-0,37} v^{-0,33} \mathrm{Fu}^{0,1} \operatorname{Pr}^{0,68} \operatorname{Pr}_{\mathrm{c}}^{-0,25}\left(\mathrm{t}_{\mathrm{c}}-\mathrm{t}\right)^{0,1} .
$$

Критеріальне рівняння тепловіддачі для турбулентної течії рідини в трубах при $\operatorname{Re}=10^{4} \ldots 5 \cdot 10^{6}$ :

$$
\mathrm{Nu}=0,021 \operatorname{Re}^{0,8} \operatorname{Pr}^{0,43} \Pi \varepsilon_{\mathrm{i}}
$$

де П $\varepsilon_{\mathrm{i}}$ - добуток поправок на конкретні умови процесу теплообміну. Наприклад, П $\varepsilon_{\mathrm{i}}=\varepsilon_{\mathrm{q}} \cdot \varepsilon_{l} \cdot \varepsilon_{\mathrm{R}}$. Поправку $\varepsilon_{l}$ на довжину $l$ коротких труб використовують, коли $l / d<50$ [6]. Якщо $l / d \geq 50 \varepsilon_{l}=1$, інакше $\varepsilon_{l}=a-b \cdot \lg (l / d)$, де a $=(1,426-3,234 / \operatorname{lgRe})^{-1}$ та $\mathrm{b}=0,5886(\mathrm{a}-1)$. Наприклад, якщо $\mathrm{Re}=10^{4}$ i $l / \mathrm{d}=2$ одержимо $\varepsilon_{l}=1,51$ (табличне значення 1,50$)$.

Для вигнутих труб поправка на радіус вигину $\mathrm{R}$ (береться по осі труби) $\varepsilon_{\mathrm{R}}=1+1,8 \mathrm{~d} / \mathrm{R}$. Наприклад, якщо $\mathrm{d}=0,01 \mathrm{~m}, \mathrm{a} \mathrm{R}=0,1 \mathrm{~m}$, то $\varepsilon_{\mathrm{R}}=1,18$.

Коефіцієнт тепловіддачі за турбулентного руху в трубі :

$$
\alpha_{\mathrm{r}}=0,021 \lambda \omega^{0,8} \mathrm{~d}^{-0,2} v^{-0,8} \operatorname{Pr}^{0,68} \operatorname{Pr}_{\mathrm{c}}^{-0,25} \varepsilon_{l} \varepsilon_{\mathrm{R}} .
$$

У перехідному (між ламінарним і турбулентним) режимі течії коефіцієнт тепловіддачі $\alpha_{\mathrm{n}}=\alpha_{\mathrm{r}} \cdot \varepsilon_{n}$, де $\varepsilon_{n}-$ поправковий коефіцієнт до $\alpha_{\mathrm{r}}$, розрахованого за формулою (13) для турбулентного режиму [7; 8].

Поправковий коефіцієнт $\varepsilon_{n}=\mathrm{a}-\mathrm{b} / \mathrm{Re}$, де $\mathrm{b}=1800-220 \lg \mathrm{gr}$ та a $=1+\mathrm{b} \cdot 10^{-4}$. Наприклад, при $\mathrm{Gr}=10^{6}$ i $\mathrm{Re}=3000$ отримаємо $\mathrm{b}=480, \mathrm{a}=1,048$ та $\varepsilon_{n}=0,888$.

Коефіцієнт чергованості (частка часу, коли має місце турбулентна течія) $\varpi=1,3-3000 / R e$. Наприклад , при $\operatorname{Re}=3000$ отримаємо $\varpi=0,3$.

Для в'язкісно-гравітаційної ламінарної течії гідравлічний опір пропорційний ๘ і важливим фактором є орієнтація труби в просторі. При турбулентній течії гідравлічний опір пропорційний $\varpi^{2}$, а орієнтація труби в просторі на $\alpha_{\mathrm{r}}$ не впливає. За перехідного режиму ламінарна і турбулентна течії почергово змінюють одна одну.

При розрахунках тепловіддачі в тубах не круглого поперечного перерізу за визначальний лінійний розмір береться еквівалентний діаметр $\mathrm{d}_{\mathrm{e}}=4 \mathrm{f} / \mathrm{P}$, де $\mathrm{f}-$ поперечний переріз каналу, ${ }^{2} ; \mathrm{P}-$ периметр поперечного перерізу, м. Коли рідина тече в кільцевому каналі, $\mathrm{d}_{\mathrm{e}}$ дорівнює різниці між зовнішнім та внутрішнім діаметрами кільцевого перерізу і вводиться поправка - відношення цих діаметрів в степені 0,18 . У випадку прямокутного перерізу каналу із сторонами а i b, $d_{e}=2 a b /(a+b)$.

За ламінарної течії шорсткість поверхні труби не впливає на $\alpha$ і гідравлічний опір. За турбулентної течії $\alpha$ в шорстких трубах може як зростати, так $\mathrm{i}$ зменшуватись порівняно з гладкими.

Розглянемо розрахунок тепловіддачі води в прямій круглій трубі з $\mathrm{d}=0,01 \mathrm{~m}$, довжиною $l=1$ м при $\omega=0,1 \mathrm{~m} / \mathrm{c}, \mathrm{t}=60^{\circ} \mathrm{C}$ i $\mathrm{t}_{\mathrm{c}}=110^{\circ} \mathrm{C}$.

Число Рейнольдса $\operatorname{Re}=0,1 \cdot 0,01 / 477 \cdot 10^{-9}=2096<2300$ і течія ламінарна. Число Грасгофа за формулою (9) $\mathrm{Gr}=9,807 \cdot 0,01^{3}(110-60) \cdot 2,33 \cdot 10^{9}=11,43 \cdot 10^{5}$. Добуток $\mathrm{Gr} \cdot \operatorname{Pr}=11,43 \cdot 10^{5} \cdot 2.98=34 \cdot 10^{5}>8 \cdot 10^{5}$. Режим течії — в'язкісно-гравітаційний. За формулою (11):

$$
\begin{aligned}
\alpha_{\mathrm{BR}} & =0,188 \cdot 0,650 \cdot 0,1^{0,33} \cdot 0,01^{-0,37}\left(477 \cdot 10^{-9}\right)^{-0,33}\left(23,3 \cdot 10^{8}\right)^{0,1} 2,98^{0,68} 1,583^{-0,25}(100- \\
-60)^{0,1} & =917 \mathrm{BT} /\left(\mathrm{M}^{2} \cdot \mathrm{K}\right) .
\end{aligned}
$$


При зростанні швидкості води вдесятеро (до 1 м/с) вдесятеро збільшиться і число Рейнольдса. За $\mathrm{Re}=20960>10^{4}$ течія стане турбулентною. 3 рівняння (13) $\alpha_{\mathrm{T}}=0,021 \cdot 0,650 \cdot 1^{0,8} \cdot 0,01^{-0,2}\left(477 \cdot 10^{-9}\right)^{-0,8} \cdot 2,98^{0,68} \cdot 1,583^{-0,25}=7385 \mathrm{BT} /\left(\mathrm{M}^{2} \cdot \mathrm{K}\right)$.

Відношення $l / \mathrm{d}=1 / 0,01=100>50$, тому поправка $\varepsilon_{l}=1$. Поправка $\varepsilon_{\mathrm{R}}=1$, тому що труба пряма.

За ламінарної течії води вздовж плоскої стінки $\left(\mathrm{Re}<4 \cdot 10^{4}\right)$ середній по поверхні стінки коефіцієнт тепловіддачі відповідає рівнянню:

звідси коефіцієнт тепловіддачі:

$$
\mathrm{Nu}=0,66 \operatorname{Re}^{0,5} \operatorname{Pr}^{0,43} \varepsilon_{\mathrm{q}}
$$

$$
\alpha_{\text {слл }}=0,66 \lambda \omega^{0,5} l^{-0,5} v^{-0,5} \operatorname{Pr}^{0,68} \operatorname{Pr}_{\mathrm{c}}^{-0,25} \text {. }
$$

При турбулентній течії вздовж плоскої стінки

звідси коефіцієнт тепловіддачі:

$$
\mathrm{Nu}=0,037 \operatorname{Re}^{0,8} \operatorname{Pr}^{0,43} \varepsilon_{\mathrm{q}},
$$

$$
\alpha_{\mathrm{cr}}=0,037 \lambda \omega^{0,8} l^{-0,2} v^{-0,8} \operatorname{Pr}^{0,68} \operatorname{Pr}_{\mathrm{c}}^{-0,25} .
$$

У рівняннях тепловіддачі за руху води вздовж плоскої стінки визначальною $\epsilon$ температура $\mathrm{t}$ набігаючого потоку, а визначальним лінійним розміром - довжина $l$ стінки в напрямі потоку.

При довжині пластини $l=1 \mathrm{~m}, \mathrm{t}=60^{\circ} \mathrm{C}, \mathrm{t}_{\mathrm{c}}=110^{\circ} \mathrm{C}$ і швидкості руху води $\omega=0,01 \mathrm{~m} / \mathrm{c}$ число Рейнольдса $\mathrm{Re}=0,01 \cdot 1 / 477 \cdot 10^{-9}=2,096 \cdot 10^{4}<4 \cdot 10^{4}$ і течія ламінарна. За формулою (15):

$$
\alpha_{\mathrm{cr}}=0,66 \cdot 0,650 \cdot 0,01^{0,5} \cdot 1^{-0,5}\left(477 \cdot 10^{-9}\right)^{-0,5} \cdot 2,98^{0,68} \cdot 1,583^{-0,25}=116,4 \mathrm{BT} /\left(\mathrm{M}^{2} \cdot \mathrm{K}\right) .
$$

Якщо швидкості води збільшиться до $1 \mathrm{~m} / \mathrm{c}$, то $\mathrm{Re}=2,096 \cdot 10^{6}$, течія буде турбулентною і за формулою (17):

$$
\alpha_{\mathrm{cI}}=0,037 \cdot 0,650 \cdot 1^{0,8} \cdot 1^{-0,2}\left(477 \cdot 10^{-9}\right)^{-0,8} \cdot 2,98^{0,68} \cdot 1,583^{-0,25}=5138 \mathrm{BT} /\left(\mathrm{M}^{2} \cdot \mathrm{K}\right) .
$$

Результати розрахунку коефіцієнтів тепловіддачі за запропонованими формулами практично збігаються з результатами прикладів розрахунку на основі критеріальних рівнянь.

Висновки. Розглянуто основні можливі варіанти тепловіддачі за вимушеного руху води в трубах, каналах і вздовж плоскої стінки. В промислових установках найчастіше має місце турбулентний режим течії. Запропоновані в статті формули $\epsilon$ простими, досить точними, не потребують використання таблиць теплофізичних параметрів води і таблиць поправок. Це полегшує та прискорює визначення коефіцієнтів тепловіддачі (в статті наведені числові приклади) та надає можливість використовувати формули у різноманітних комп'ютерних програмах типових процесів тепловіддачі.

\section{ЛИТЕРАТУРА}

1. Константінов С. М. Теоретичні основи теплотехніки: підручник/ С. М. Константінов, С. М. Панов. — К.: «Золоті ворота», 2012. - 592 с.

2. Беляев Н. М. Основы теплопередачи: учебник / Н. М. Беляев. - К.: Выща шк. Головное изд-во, 1989. - 343 с.

3. Теоретические основы теплотехники. Теплотехнический эксперимент: справочник: в 4 кн. Кн.2. Теплоэнергетика и теплотехника / под общ. ред. В. А. Григорьева, В. М. Зорина. - М.: Энергоатомиздат, 1988. - 560 с..

4. Физические величины: справочник/ Под ред. И. С. Григорьева, Е. 3. Мейлихова. М.: Энергоатомиздат, 1991. - $1232 \mathrm{c}$. 
5. Александров А. А. Таблицы теплофизических свойств воды и водяного пара.: справочник. Рек ГСССД Р-776-98 / А. А. Александров, В. А. Григорьев. - М.: Изд-во МЭИ, 1999. - 168 с.

6. Сінат-Радченко Д. Є. Вплив довжини труби на тепловіддачу за різних режимів вимушеного руху рідини в трубах / Д. С. Сінат-Радченко, С. М. Василенко, Н. В. Іващенко // Цукор України. — 2015. - № 10. - С. 21-22.

7. Василенко С. М. Основи тепломасообмену: підручник / С. М. Василенко, А. І. Українець, В. В. Олішевський. - К.: НУХТ, 2004. — 250 с.

8. Сінат-Радченко Д. С. Тепловіддача при перехідному режимі течії рідини у горизонтальних трубах / Д. Є. Сінат-Радченко, С. М. Василенко, О. М. Недбайло // Промышленная теплотехника. — 2014. — Т.36, № 6. - С. 46-48.

\title{
ТЕПЛООТДАЧА ПРИ ВЫНУЖДЕННОМ ДВИЖЕНИИ ВОДЫ В ТРУБАХ, КАНАЛАХ И ВДОЛЬ ПЛОСКОЙ СТЕНКИ
}

\author{
Д. Е. Синат-Радченко, Н. В. Иващенко, С. М. Василенко \\ Национальный университет пищевых технологий
}

На основе обобщения данных по теплофизическим свойствам воды и анализа ее теплоотдачи при вынужденном движении в трубах, каналах и вдоль плоской стенки для интервала температур $0 \ldots 130^{\circ} \mathrm{C}$, разных условий и режимов движения предложено ряд простых, но достаточно точных, формул (а также числовые примеры их использования) относительно расчета коэффрициентов теплоотдачи без использование каких-либо таблиц и интерполяции. Это облегчает и ускоряет инженерные расчеты и дает возможность использовать форомулы в разнообразных компьютерных программах.

Ключевые слова: вода, вынужденное движение, трубы и каналы, плоские стенки, режимы течения, коэффрициенты теплоотдачи. 